\title{
Czech Historical Atlas: Creation of a web map portal
}

\author{
Petra Jílkováa, ${ }^{\mathrm{a},}$, Jiř́i Krejčí ${ }^{\mathrm{b}}$ \\ ${ }^{a}$ Czech Technical University in Prague, Faculty of Civil Engineering, Department of Geomatics, Czechia, petra.jilkova@fsv.cvut.cz \\ ${ }^{b}$ Czech Technical University in Prague, Faculty of Civil Engineering, Department of Geomatics, Czechia, jirikrejci@fsv.cvut.cz \\ * Corresponding author: petra.jilkova@fsv.cvut.cz
}

Keywords: historical atlas, web map portal, web application, historical cartography, Czech Historical Atlas

\begin{abstract}
:
The web map portal Czech Historical Atlas presents selected historical topics from two printed historical atlases Czech Historical Atlas (Semotanová et al., 2019) and Academic Atlas of Czech History (Semotanová et al., 2014), both published within the long-term cooperation of a team of cartographers from the Department of Geomatics, CTU in Prague, and a team of historians from the Institute of History of the Academy of Sciences. The content of the portal is divided into eight chapters, namely Borders and Territories, Borders and Regions, the Czech State and Europe in the 20th Century, Populations, Religion and Faith, Historical Milestones, Periods and Consequences, War Conflicts and Their Consequences, and Landscape and Humans. Each of the chapters is further divided into several subchapters, which represent separate web map applications presenting a set of temporally or thematically related maps (see Fig. 1). Map applications are supplemented by accompanying texts and illustrations, which significantly complement the thematic content of maps.
\end{abstract}

Map applications offer the user the standard interactive functions such as zooming, turning on the overall view or switching layers. Moreover, the advanced functionality (element highlighting, information pop-up window, time slider, data filtering by selected attribute or interactive comparison of two or more maps) is added for each single map separately in accordance with its thematic content. Web applications use the Esri WebMap entity as a basis. The web portal, including individual map applications, is built on standard web technologies HTML, CSS, JavaScript and PHP.

Web map applications are based on maps originally created only for printed atlases. Therefore, the attribute data needed to be enriched in order to display additional information in pop-up windows. It was often necessary to completely redesign the original overly complex map symbology for the presentation of maps in the web environment. The complex symbology was partially substituted by advanced map application functionality such as time slider or filtering.

With regard to a large number of maps (more than 160), a methodological procedure was created for map editing, including determining the scale levels, setting rules for sign key and fonts, as well as preparing data visualizations for interactive functions of the web application. In order to provide the comparisons of different web maps, it was necessary to unify the scale series and cartographic representations of maps depicting the territory of the Czech lands at various stages of historical development. Two basic scale series were selected for the geographical scope of the Czech lands and a separate scale series was chosen for the territory of Europe or its part. The maximum zoom level was chosen individually for each web map with respect to the level of detail and generalization of the original data.

To provide the advanced functionality (see above), the map layers were divided into thematic and background layers within the map project. Thematic layers represent the active content of the map, over which a certain functionality can be applied (attribute querying, layer filtering according to the specified attribute, change in time, etc.). The modified map project was published as a dynamic map service on a separate ArcGIS Server, which allows handling layers and attributes using the ArcGIS API for JavaScript. Final web map was created and saved in the ArcGIS Online environment.

During the publication, several obstacles emerged, resulting from the limits of the ArcGIS Online technology. Certain layers, more complex map symbology or cartographic methods used for printed maps could not be correctly rendered in the web environment. Therefore, a compromise solution between map functionality and the complexity of cartographic representation of some phenomena had to be accepted.

The map portal Czech Historical Atlas represents a unique and modern way of presenting historical topics in the web environment. Creating such a map portal is a very complex process. First of all, it is necessary to create an overall concept of the portal, to select and structure individual topics and to choose an effective way of their presentation. Great attention must be paid to the way of presentation of map content, which is the basis of the entire web portal. Another important step in this context is the selection of appropriate web technology and functionality of map applications, which will define the possibilities and limits of presentation of map content. Map content must be adapted (if originally intended for printing) to the web environment, which brings considerable complications. Frequently, it is necessary to 
make fundamental changes of the cartographic representation of selected phenomena in order to maintain the intended functionality of the map application, which can often reduce the cartographic and aesthetic value of the original map.

The map portal is available in Czech and English versions at www.czechhistoricalatlas.cz.

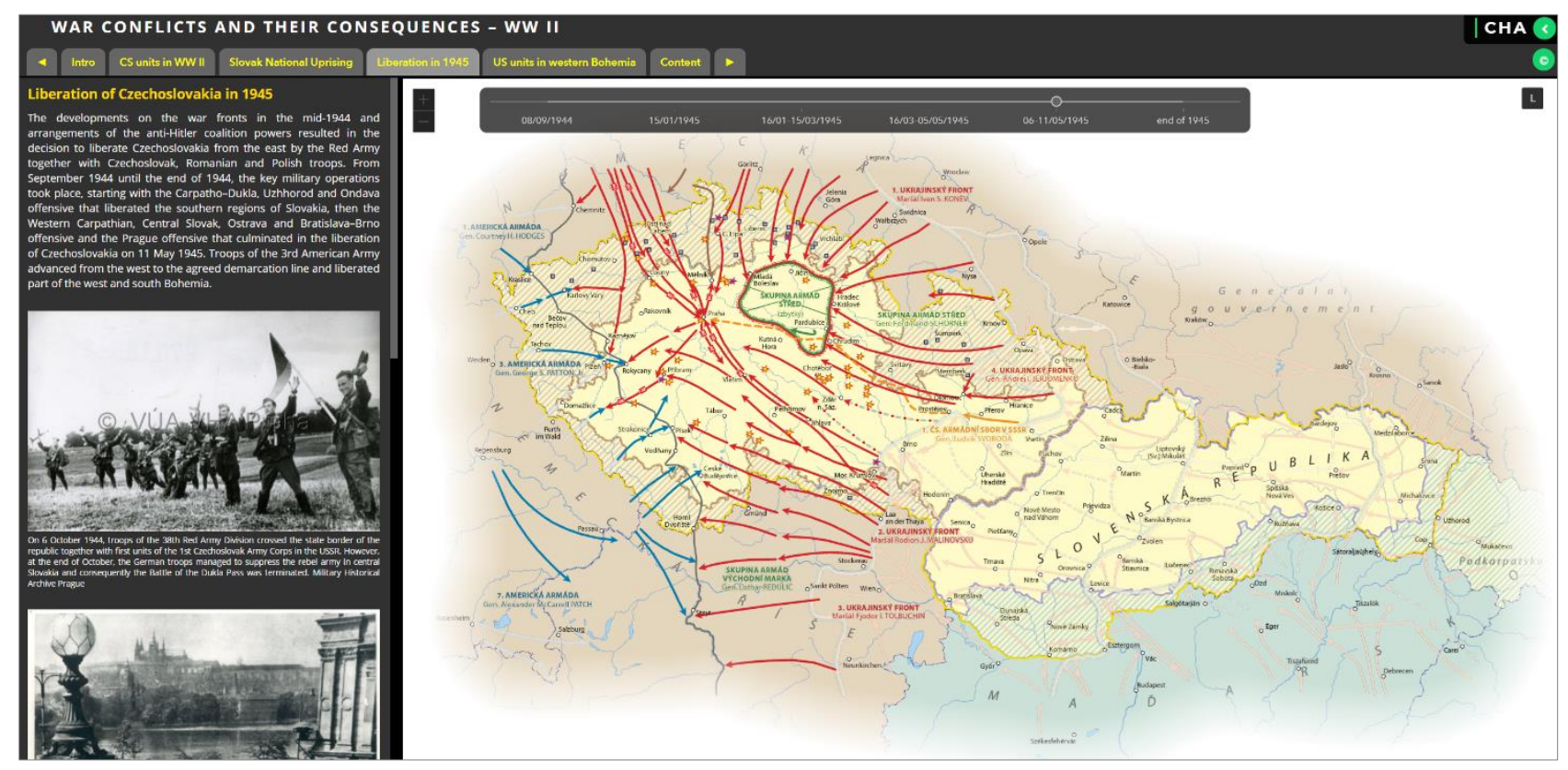

Figure 1. Web map application presenting a set of thematically related maps.

\section{Acknowledgements}

This work was supported by the Grant Agency of the Czech Technical University in Prague, grant No. SGS21/054/OHK1/1T/11.

\section{References}

Semotanová, E., Cajthaml, J., Seemann, P. et al., 2014. Academic Atlas of Czech History (Akademický atlas českých dějin, in Czech). Prague: Academia, ISBN 978-80-200-2182-3, 559 p.

Semotanová, E., Zudová, Z., Močičková, J., Cajthaml, J., Seemann, P., Bláha, J. D. et al., 2019. Czech Historical Atlas. Chapters on the History of the 20th Century (Český historický atlas. Kapitoly z dějin 20. století, in Czech) Prague: Institute of History Publishing, ISBN 978-80-7286-346-4, 297 p. 